\title{
Konservasi Keanekaragaman Jenis Tumbuhan Jawa di Kebub Raya Baturraden di Kawasan Bekas Hutan Produksi Terbatas
}

\author{
Herawikan Mandiriati, Djoko Marsono, Erny Poedjirahajoe, Ronggo Sadono
}

Program Doktor Ilmu Kehutanan, Fakultas Kehutanan UGM, Yogyakarta

Seksi Perencanaan Hutan II Perum Perhutani JL Argulobang no 3 Yogyakarta

Kebun Raya Baturraden, Baturraden Purwokerto

email: Herawikan1964@yahoo.co.id

\begin{abstract}
ABSTRAK
Pengeloaan Kebun Raya Baturraden di Kawasan Hutan Produksi terbatas dapat menimbulkan permasalahan surface run off apabila penanganan lokasi tidak dilakukan secara konservatif. Penelitian ini bertujuan untuk mengatasi problematika Perubahan ekositem Hutan Produksi Terbatas yang bersifat homogen menjadi Kebun Raya Baturraden merupakan hutan heterogen. Dengan cara membuat PU (Petak Ukur) di zona pemanfaatan keluasan 77,4 Ha, sebanyak 109 PU (Petak Ukur) dengan ukuran 20x20 m, intensitas 5,5, jarak antar PU 1, 3 m. Hasil pengamatan parameter yang menjadi pertimbangan ketinggian tanah antara 1076-760 Dpl, kelerengan tanah $12^{\circ}-30^{\circ}$, kedalaman tanah $<85 \mathrm{Cm}-90<$, erodibilitas tanah 0,43 , jenis tanah Latosol Coklat dan curah hujan rata-rata $5.600 \mathrm{~mm}$ per tahun. Dari hasil pengamatan kawasan Kebun Raya Baturraden tanah mudah sekali terjadi proses surface run off. Mengatasi dan merubah ekosistem dari hutan homogeny menjadi heterogen (1) penjarangan harus bertahap sesuai lahan yang akan dikelola, (2) Dengan kondisi tegakan pohon sangat rapat untuk melakukan tebangan sebaiknya menggunakan tebangan penerangan atau penjarangan jangan sampai tanah terbuka mengingat mempunyai curah hujan rata-rata $5.600 \mathrm{~mm}$ per tahun. (3) pada lokasi tertentu yang rawan terjadi erosi harus dibuat terasering untuk mengurangi terjadinya surface run off.
\end{abstract}

Kata Kunci: Kebun Raya, Hutan Produksi terbatas surface run off, ekosistem

\begin{abstract}
Managing Baturraden Botanical Garden in the Limited Production Forest Area can cause problems of surface run off if the location is not handled conservatively. This study aims to overcome the problem of ecosystem changes of the homogeneous Limited Production Forest to become Baturraden Botanical Garden which is heterogeneous forest by making PU (sample plots) in the utilization zone of 77.4 hectares in breadth, a total of 109 PU (sample plots) with a size of $20 \times 20 \mathrm{~m}$, intensity of 5.5, the distance between PU's 1, $3 \mathrm{~m}$. The parameters taken into consideration, as a result of observation, are the height of land between 1076-760 above sea level, land slope between $30^{\circ} 12^{\circ}$, land depth $<85 \mathrm{~cm}-90<$, soil erodibility 0.43 , Brown Latosol soil type and an average rainfall of 5,600 mm per year. From the observation of Baturraden Botanical Garden area, it was observed that land surface run off processes easily occur. To overcome and change the ecosystem of the forest, from homogeneous to heterogeneous: (1) thinning should be phased in accordance to the land to be managed, (2) with the condition of very tight tree stands to be felled, lighting felling or thinning should be done without exposing the land considering the rainfall average of 5,600 $\mathrm{mm}$ per year. (3) In certain locations that are prone to erosion terracing must be made to reduce the occurrence of surface run-off.
\end{abstract}

Key words: Botanical Garden, limited production forest, surface run-off, ecosystem.

Cara sitasi: Mandiriati, H., Marsono, D., Poedjirahajoe, E., Sadono, R. (2016). Konservasi Keanekaragaman Jenis Tumbuhan Jawa di Kebub Raya Baturraden di Kawasan Bekas Hutan Produksi Terbatas. Jurnal Ilmu Lingkungan. 14(1),33-38, doi:10.14710/jil.14.1.33-38

\section{PENDAHULUAN}

Berbagai Kebun Raya di dunia menyimpan koleksi tumbuhan hidup serta merupakan sumber penting untuk upaya pelestarian tumbuhan, didunia tersebar 1600 Kebun raya dengan koleksi sekitar 4 juta tumbuhan yang mewakili 80.000 spesies atau sekitar 30\% flora yang ada didunia (Given
1995; Heywood 1995). Kebun Raya terbesar di dunia milik kerajaan Inggris di Kew diperkiraakan memiliki 25.000 spesies tumbuhan yang dibudidayakan atau sekitar 10 $\%$ dari jumlah spesies yang ada di dunia dan 2.700 diantaranya berstatus genting atau terancam punah menurut katagori IUCN. Kebun Raya ini memainkan peran penting dalam riset 
dan memberi pelatihan, terutama konservasi tumbuhan dan hortikultur. Salah satu Kebun Raya baru adalah proyek Eden dibarat daya Inggris yang melalui koleksi rumah kacanya menyimpan dan menampilkan lebuh dari 5000 spesies yang penting secara ekonomi.

Kebun Raya di Indonesia tengah meningkatkan upaya pembudidayaan spesies langka dan terancam punah. Banyak pula yang mengkhususkan dari tipe - tipe tumbuhan tertentu. Kebun Raya diharapkan dapat memberikan sumbangan yang berharga bagi upaya konservasi, karena koleksi tumbuhan hidup dan spesies merupakan sumber informasi terbaik mengenai penyebaran tumbuhan dan pengenalan tumbuhan dan penelaahan status konservasi spesies.Kebun Raya Indonesia membutuhkan minimal 45 Kebun Raya. Saat ini ada 16 Kebun Raya yang sedang dibangun di 14 provinsi, 4 Kebun Raya yang sudah eksis (Anonim, 2007).

Kondisi pulau Jawa yang berpenduduk terpadat di Indonesia sehingga di pulau Jawa banyak menghadapi masalah dalam mempertahankan kelestarian sumberdaya alamnya. Tekanan hutan yang semakin kuat karna terjadi konversi hutan yang begitu cepat berubah menjadi berbagai macam kepentingan masyarakat untuk pemukiman, sarana transportasi, dan sarana publik lainnya, dan pertumbuhan penduduk yang tinggi, maka kawasan hutan di Jawa tinggal 19\%, mengingat kondisi tersebut perlu segera diupayakan pelestarian keanekaragaman hayati agar tidak mengalami kepunahan. Salah satu tujuan untuk memenuhi kebutuhan setiap provinsi minimal mempunyai satu Kebun Raya dan menghadapi berbagai permasalahan tekanan terhadap hutan di pulau Jawa khususnya Jawa Tengah maka dipilih Baturraden untuk lokasi Kebun Raya sebagai kawasan konservasi Ex- situ flora pegunungan Jawa (anonim, 2012)

Kebun Raya Baturraden diresmikan sebagai Kebun Raya 29 Desember 2004 oleh Gubernur Jawa Tengah kemudian dikuatkan dengan SK Menhut No 85/ Menhut-II/ 2005 tanggal 4 April 2005. Lokasi kawasan yang di pilih seluas 143,5 Ha di petak 1 dan 3 berupa (HPT) Hutan Produksi Terbatas, secara geografis Kebun Raya Baturaden terletak diantara 109o 14'30" LS - 10915'00" LS dan

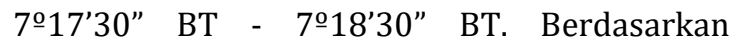
administrasi pengelolaan hutan terletak di Resort Pemangkuan Hutan (RPH) Baturraden, Bagian Kesatuan Pemangkuan Hutan (BKPH) Gunung Slamet Barat, Bagian Hutan (BH) Gunung Slamet, Kesatuan Pemangkuan Hutan Banyumas Timur, Perum Perhutani. Secara administratif kawasan Kebun Raya ini berada di Desa Kemutug Lor, Kecamatan Baturraden, Kabupaten Banyumas, berbatasan dengan
Lokawisata Baturraden dan Bumi Perkemahan Baturraden.

Pembangunan Kebun Raya Baturraden merupakan cara pemerintah untuk Peyelamatan kelestarian tumbuh-tumbuhan. Pemilihan lokasi tersebut memunculkan berbagai permasalahan yang harus di tangani secara pertimbangan konservatif, mengingat sebelum ditunjuk menjadi Kebun Raya Baturraden kawasan tersebut adalah HPT (Hutan Produksi Terbatas), merupakan hutan monokultur didominasi tanaman Damar ( Agathis Alba), karna sebelumnya ditetapkan sebagai HPT (Hutan Produksi Terbatas) Perhutani hanya memanfaatkan sebatas penyadapan getah Damar ( berusia antara $10-64$ tahun. Mengingat peraturan HPT (Hutan Produksi Terbatas) Tahun 2010 pasal 1 : Hutan Produksi Terbatas adalah kawasan hutan dengan faktor-faktor kelas lereng, jenis tanah, dan intensitas hujan setelah masing-masing dikalikan dengan angka penimbang mempunyai jumlah nilai antara 125174, di luar kawasan hutan lindung, hutan suaka alam, hutan pelestarian alam, dan taman buru, sedangkan Peraturan Presiden no 93 Tahun 2011 pasal 1 menyebutkan: (1) Kebun Raya adalah kawasan konservasi tumbuhan secara $e x$ situ yang memiliki koleksi tumbuhan terdokumentasi dan ditata berdasarkan pola klasifikasi taksonomi, bioregion, tematik, atau kombinasi dari pola-pola tersebut untuk tujuan kegiatan konservasi, penelitian, pendidikan, wisata dan jasa lingkungan.

Perubahan Hutan Produksi Terbatas dengan karakter hutan monokultur menjadi Kebun Raya sebagai kawasan konservasi tumbuhan secara ex-situ berarti merubah karakter dari hutan monokultur menjadi heterogen sehingga dalam proses pengelolaan harus mempertimbangkan beberapa hal mengingat kawasan Kebun Raya Baturraden mempunyai kelas lereng, jenis tanah, ketinggian tanah, kedalaman tanah dan intensitas hujan yang menjadi pertimbangan pemerintah sehingga kawasan tersebut di masukan kedalam Hutan Produksi terbatas (HPT). Kondisi lokasi Kebun Raya Baturraden harus dikelola secara koservatif.

\section{METODE PENELITIAN}

Dalam penelitian ini digunakan metode survei, pada umumnya pengertian survei dibatasi pada pengertian survey sampel, informasi dikumpulkan dari sebagian populasi (sampel) untuk mewakili seluruh populasi. Tahapan yang ditempuh untuk mendapat data potensi hutan dalam penelitian di lapangan dengan cara memilih lokasi di zona pemanfaatan seluas 77,4 Ha kemudian membuat Petak Ukur (PU), sket pada peta 1: 
Mandiriati, H., Marsono, D., Poedjirahajoe, E., Sadono, R. (2016). Konservasi Keanekaragaman Jenis Tumbuhan Jawa di Kebub Raya Baturraden di Kawasan Bekas Hutan Produksi Terbatas. Jurnal Ilmu Lingkungan. 14(1),33-38, doi:10.14710/jil.14.1.33-38

10.000, membuat Petak Ukur (PU) berukuran 20 × 20 meter dengan intensitas 5,5\% dalam setiap Petak Ukur ( PU ) jarak antar PU 1,3 cm di peta dalam setiap Petak Ukur (PU) sehingga di lapangan dihasilkan jumlah 109 PU jarak antar PU $130 \mathrm{~m}$ di lapangan dilakukan pengukuran dan penilaian meliputi : Jumlah pohon, jenis pohon, rata2 tinggi pohon, ketinggian tanah, kedalaman tanah, kelerengan tanah, erodibilitas tanah dan jenis tanah.
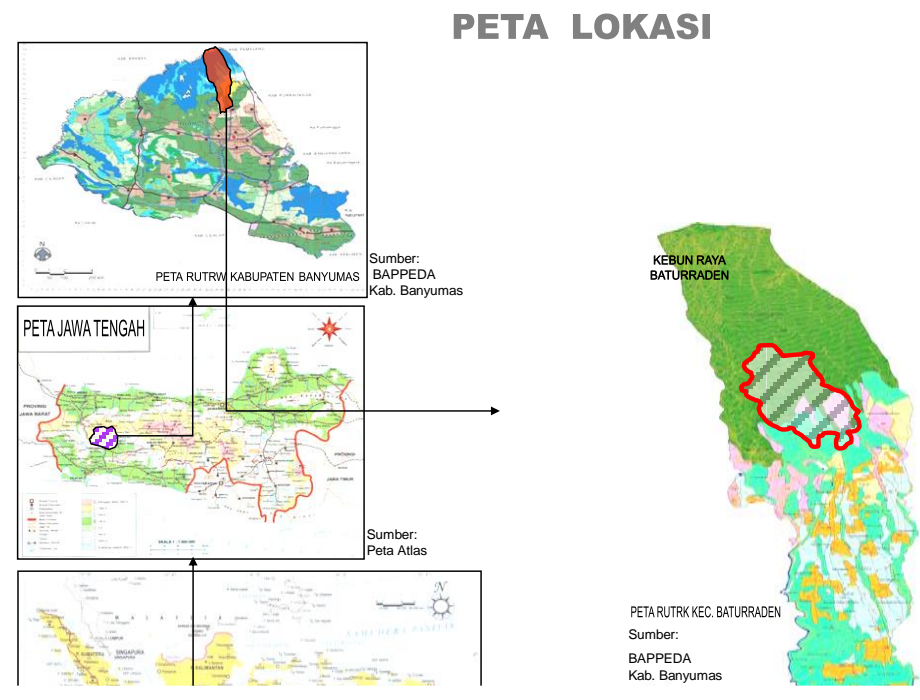

Gambar 1. Peta Lokasi Penelitian Kebun Raya Baturraden

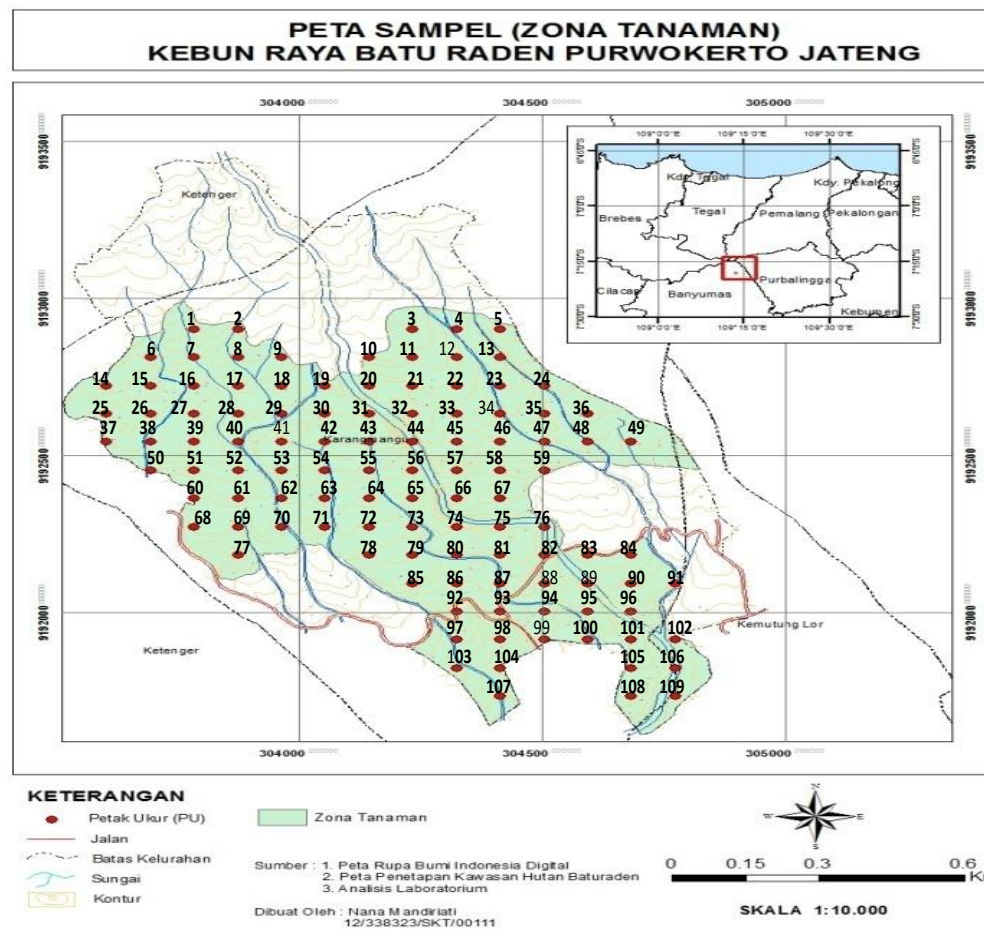

Gambar 2. Peta Petak Ukur (PU) Lokasi Penelitian

\section{HASIL DAN PEMBAHASAN}

Penelitian ini bertujuan untuk memberi kajian pengelola Kebun Raya Baturraden untuk mempertimbangkan beberapa hal yang menyangkut kodisi kawasan mulai dari jenis tanah, tingkat erodibilitas, kedalaman tanah, ketinggian, kelerengan, dan curah hujan sehingga kondisi ini dapat dipakai untuk membuat pengelolaan Kebun Raya Baturraden agar tidak terjadi erosi lahan selama proses perubahan Hutan Produksi Terbatas (HPT) menjadi Kebun Raya. Hal-hal yang menjadi pertimbangan : 


\subsection{Jenis tanah dan tingkat Erodibilitas}

Ketahanan tanah merupakan salah satu faktor penentu besarnya erosi. Makin tinggi nilai indeks erodibilitas tanah $(\mathrm{K})$, makin rendah ketahanan tanah sehingga semakin mudah pula tanah tererosi. Lahan hutan, pertanian monokultur dan lahan pertanian turnpangsari pada kelerengan yang sama memiliki tingkat erosi yang berbeda. Sifat fisiknya tanah faktor lain yang menentukan besarya erosi, meliputi kelerengan, permeabilitas, tekstur dan struktur tanah (Hardjowigeno, 2003). Jenis tanah di Kebun Raya Baturraden Latosol coklat jenis tanah ini mempunyai nilai erodibilitas (factor $\mathrm{K}$ ) 0.43 sedangkan erodibilitas (nilai $\mathrm{K}$ ) antara 0,410,55 menurut table erodibilitas tanah yang diklasifikasi USDA (1973) termasuk erodibilitas tinggi sehingga sifat tanah di Kebun Raya Baturraden mudah tererosi, untuk melakukan pengelolaan kawasan Kebun Raya Baturraden sifat tanah yang mudah tererosi harus menjadi kebijakan pengelola dalam membuka lahan membagi menjadi zona- zona sesuai aturan Kebun Raya di Peraturan Presiden Republik Indonesia no 93 tahun 2011 peraturan tentang Kebun Raya.

\subsection{Pengaruh Kelerengan dan ketinggian terhadap kecepatan erosi tanah.}

Kelerengan kawasan Kebun Raya Baturraden dari PU 1-108 antara 12॰-30。 bergelombang, berbukit, agak curam, dan mempunyai ketinggian dari $1076-760 \mathrm{dpl}$. Dalam kawasan Kebun Raya Baturraden terdapat beberapa sungai kering kondisi yang saling mendukung antara kelerengan dan ketinggian akan memudahkan terjadinya proses surface run off, Lahan yang mempunyai kemiringan dapat lebih mudah terganggu atau rusak karena dipengaruhi oleh curah hujan yang dapat menyebabkan kelongsoran tanah , tanah-tanah lapisan atas yang subur akan terhanyut.( Andrian, Supriadi, Marpaung Purba, 2014). Tanah yang subur akan mengalir ke sungai bersama air hujan menuju dataran yang lebih rendah. Hujan menimbulkan aliran di daratan, baik aliran permukaan maupun aliran di dalam tanah. Disamping itu hujan yang menjadi limpasan pada permukaan sungai secara otomatis akan mengerosi lapisan atas lahan, yang selanjutnya akan dibawa ke palung sungai. Oleh sebab itu untuk memprediksi volume sedimen yang dibawa oleh sungai sangat tergantung kondisi sungai dan pola hujan yang terjadi (NatakusumahDK, M. Syahril B. Kusuma, Darmawan H, Adityawan M \& Farid M, 2007).

Tabel 1 Tabel Ketinggian dan Kelerengan Kebun Raya Baturraden.

\begin{tabular}{|c|c|c|c|c|c|c|c|c|c|c|c|}
\hline No & Ketinggian & Kelerengan & No & Ketinggian & Kelerengan & No & Ketinggian & Kelerengan & No & \begin{tabular}{|l|} 
Ketinggian \\
\end{tabular} & Kelerengan \\
\hline PU & Dpl & $\circ$ & PU & Dpl & - & PU & Dpl & . & PU & Dpl & $\circ$ \\
\hline 1 & 983 & 20 & 29 & 967 & 20 & 57 & 875 & 19 & 85 & 822 & 28 \\
\hline 2 & 984 & 20 & 30 & 930 & 29 & 58 & 875 & 19 & 86 & 822 & 28 \\
\hline 3 & 984 & 20 & 31 & 930 & 29 & 59 & 876 & 23 & 87 & 822 & 28 \\
\hline 4 & 985 & 20 & 32 & 930 & 29 & 60 & 898 & 28 & 88 & 851 & 20 \\
\hline 5 & 983 & 20 & 33 & 930 & 29 & 61 & 898 & 28 & 89 & 852 & 30 \\
\hline 6 & 981 & 33 & 34 & 930 & 29 & 62 & 898 & 28 & 90 & 852 & 30 \\
\hline 7 & 981 & 33 & 35 & 930 & 29 & 63 & 898 & 28 & 91 & 812 & 12 \\
\hline 8 & 981 & 33 & 36 & 930 & 29 & 64 & 898 & 28 & 92 & 852 & 30 \\
\hline 9 & 981 & 33 & 37 & 959 & 20 & 65 & 898 & 28 & 93 & 852 & 30 \\
\hline 10 & 981 & 33 & 38 & 959 & 20 & 66 & 898 & 28 & 94 & 826 & 30 \\
\hline 11 & 981 & 33 & 39 & 942 & 25 & 67 & 898 & 28 & 95 & 806 & 31 \\
\hline 12 & 981 & 33 & 40 & 941 & 28 & 68 & 822 & 28 & 96 & 812 & 12 \\
\hline 13 & 981 & 33 & 41 & 942 & 25 & 69 & 822 & 28 & 97 & 806 & 31 \\
\hline 14 & 1076 & 22 & 42 & 942 & 25 & 70 & 822 & 28 & 98 & 806 & 31 \\
\hline 15 & 967 & 20 & 43 & 959 & 20 & 71 & 822 & 28 & 99 & 852 & 30 \\
\hline 16 & 967 & 20 & 44 & 890 & 16 & 72 & 851 & 20 & 100 & 763 & 12 \\
\hline 17 & 967 & 20 & 45 & 890 & 16 & 73 & 818 & 30 & 101 & 763 & 12 \\
\hline 18 & 930 & 29 & 46 & 890 & 16 & 74 & 818 & 30 & 102 & 763 & 12 \\
\hline 19 & $\mathbf{9 3 0}$ & 29 & 47 & 890 & 16 & 75 & 852 & 30 & 103 & 763 & 12 \\
\hline 20 & 930 & 29 & 48 & 890 & 16 & 76 & 852 & 30 & 104 & 763 & 12 \\
\hline 21 & 967 & 20 & 49 & 890 & 16 & 77 & 852 & 30 & 105 & 763 & 12 \\
\hline 22 & 930 & 29 & 50 & 959 & 20 & 78 & 816 & 31 & 106 & 763 & 12 \\
\hline 23 & 930 & 29 & 51 & 941 & 28 & 79 & 826 & 30 & 107 & 763 & 12 \\
\hline 24 & 930 & 29 & 52 & 941 & 28 & 80 & 806 & 31 & 108 & 769 & 13 \\
\hline 25 & 1076 & 22 & 53 & 941 & 28 & 81 & 860 & 21 & 109 & 760 & 30 \\
\hline 26 & 967 & 20 & 54 & 941 & 28 & 82 & 860 & 21 & & & \\
\hline 27 & 967 & 20 & 55 & 941 & 28 & 83 & 851 & 20 & & & \\
\hline 28 & 967 & 20 & 56 & 940 & 28 & 84 & 851 & 20 & & & \\
\hline
\end{tabular}

Lereng yang semakin curam dan semakin panjang akan meningkatkan kecepatan aliran permukaan dan volume air permukaan semakin besar, sehingga benda yang bisa diangkut akan lebih banyak (Martono, 2006). Salah satu upaya untuk Mengurangi tingkat bahaya erosi pada kemiringan lahan dengan cara pembuatan teras (Kartasapoetra, dkk, 1987). 
Mandiriati, H., Marsono, D., Poedjirahajoe, E., Sadono, R. (2016). Konservasi Keanekaragaman Jenis Tumbuhan Jawa di Kebub Raya Baturraden di Kawasan Bekas Hutan Produksi Terbatas. Jurnal Ilmu Lingkungan. 14(1),33-38, doi:10.14710/jil.14.1.33-38
3.3. Berkurangnya kedalaman tanah menunjukkan sudah terjadi erosi tanah
Kebun Raya Baturraden pada zona pemanfaatan dengan keluasan 77,4 Ha dari PU 1-109 mempunyai kedalaman tanah antara $<75$ s.d $>90 \mathrm{~cm}$ dari pengamatan data diatas PU yang mempunyai dpl lebih tinggi rata-rata
mempunyai kedalaman tanah kurang dari $90 \mathrm{~cm}$ keadaan ini menunjukkan terjadinya erosi tanah secara perlahan, erosi yang terjadi secara berlahan- lahan karna masih tertahan tegakan tanaman damar yang sangat rapat, kondisi ini akan memacu runoff semakin cepat apabila tidak dilakukan pengelolaan secara koservatif.

Tabel 2. Tabel Kedalaman Tanah

\begin{tabular}{|c|c|c|c|c|c|c|c|c|c|c|c|}
\hline No & $\begin{array}{c}\text { Kedalaman } \\
\text { Tanah }\end{array}$ & No & $\begin{array}{c}\text { Kedalaman } \\
\text { Tanah }\end{array}$ & No & $\begin{array}{c}\text { Kedalaman } \\
\text { Tanah }\end{array}$ & No & $\begin{array}{c}\text { Kedalaman } \\
\text { Tanah }\end{array}$ & No & $\begin{array}{c}\text { Kedalaman } \\
\text { Tanah }\end{array}$ & No & $\begin{array}{c}\text { Kedalaman } \\
\text { Tanah }\end{array}$ \\
\hline PU & $(\mathrm{Cm})$ & PU & $(\mathrm{Cm})$ & PU & $(\mathrm{Cm})$ & PU & $(\mathbf{C m})$ & PU & $(\mathrm{Cm})$ & PU & ( Cm) \\
\hline 1 & $<75$ & 20 & $<85$ & 39 & $>90$ & 58 & $<80$ & 77 & $>90$ & 96 & $>90$ \\
\hline 2 & $<75$ & 21 & $<80$ & 40 & $<75$ & 59 & $<80$ & 78 & $>90$ & 97 & $<85$ \\
\hline 3 & $<75$ & 22 & $<85$ & 41 & $>90$ & 60 & $<85$ & 79 & $>90$ & 98 & $<85$ \\
\hline 4 & $<75$ & 23 & $<85$ & 42 & $>90$ & 61 & $<85$ & 80 & $<85$ & 99 & $>90$ \\
\hline 5 & $<75$ & 24 & $<85$ & 43 & $<80$ & 62 & $<85$ & 81 & $>90$ & 100 & $>90$ \\
\hline 6 & $<80$ & 25 & $<75$ & 44 & $<85$ & 63 & $<85$ & 82 & $>90$ & 101 & $>90$ \\
\hline 7 & $<80$ & 26 & $<80$ & 45 & $<85$ & 64 & $<85$ & 83 & $<85$ & 102 & $>90$ \\
\hline 8 & $<80$ & 27 & $<80$ & 46 & $<85$ & 65 & $<85$ & 84 & $<85$ & 103 & $>90$ \\
\hline 9 & $<80$ & 28 & $<80$ & 47 & $<85$ & 66 & $<85$ & 85 & $>90$ & 104 & $>90$ \\
\hline 10 & $<80$ & 29 & $<80$ & 48 & $<85$ & 67 & $<85$ & 86 & $>90$ & 105 & $>90$ \\
\hline 11 & $<80$ & 30 & $<85$ & 49 & $<85$ & 68 & $>90$ & 87 & $>90$ & 106 & $>90$ \\
\hline 12 & $<80$ & 31 & $<85$ & 50 & $<80$ & 69 & $>90$ & 88 & $<85$ & 107 & $>90$ \\
\hline 13 & $<80$ & 32 & $<85$ & 51 & $<75$ & 70 & $>90$ & 89 & $>90$ & 108 & $>90$ \\
\hline 14 & $<75$ & 33 & $<85$ & 52 & $<75$ & 71 & $>90$ & 90 & $>90$ & 109 & $>90$ \\
\hline 15 & $<80$ & 34 & $<85$ & 53 & $<75$ & 72 & $<85$ & 91 & $>90$ & & \\
\hline 16 & $<80$ & 35 & $<85$ & 54 & $<75$ & 73 & $>90$ & 92 & $>90$ & & \\
\hline 17 & $<80$ & 36 & $<85$ & 55 & $<75$ & 74 & $>90$ & 93 & $>90$ & & \\
\hline 18 & $<85$ & 37 & $<80$ & 56 & $<75$ & 75 & $>90$ & 94 & $>90$ & & \\
\hline 19 & $<85$ & 38 & $<80$ & 57 & $<80$ & 76 & $>90$ & 95 & $<85$ & & \\
\hline
\end{tabular}

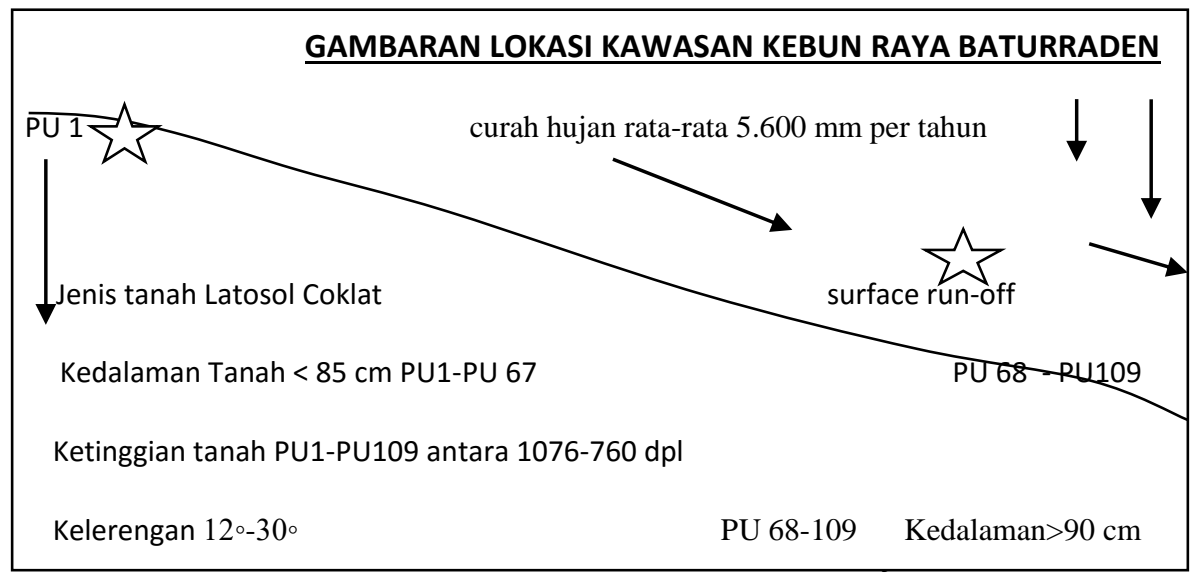

\section{KESIMPULAN}

Pengelolaan Kebun Raya Baturraden dihadapkan pada berbagai masalah yang harus diatasi secara konservatif, mengingat Kebun Raya Baturraden adalah kawasan konservasi tumbuhan untuk menyelamatkan berbagai tanaman khususnya di Jawa, dari hasil penelitian dapat disimpulkan: a) Kebun Raya Baturraden mempunyai jenis tanah Latosol coklat jenis tanah ini mempunyai nilai erodibilitas dengan kriteria tinggi artinya tanah kawasan Kebun Raya Baturraden mudah tererosi. b) Kebun Raya Baturraden pada zona pemanfaatan mempunyai rata-rata kelerengan bergelombang, berbukit, agak curam, dan mempunyai ketinggian dari 1076 - 760 dpl. c) Kedalaman tanah di zona pemanfaatan dengan bervariasi pada PU 1-67 kedalaman rata-rata masuk kriteria kedalaman tanah sedang dan PU 68-109 termasuk kriteria tanah dalam.

Kalau dilihat dari hasil pengamatan data diatas kondisi Kawasan Kebun Raya 
Baturraden mudah sekali tererosi. Erosi tanah sudah mulai terjadi dapat dilihat dari kedalaman tanah bagian atas masuk kriteria sedang semakin kebawah masuk kriteria dalam. Erosi tanah saat ini bisa terkendali oleh kerapatan tegakan pohon Damar yang cukup tinggi. Sehingga pemilihan lokasi kawasan Kebun Raya Baturraden di petak 1 dan 3 kurang tepat menginngat lokasi tersebut bekas Hutan Produksi Terbatas dengan tegakan tanaman homogen berupa pohon Damar, Perhutani selama ini dalam memanfaatkan potensi Sumber Daya Hutan hanya terbatas pada pengambilan getah Damar dan tidak masuk dalam lokasi rotasi tebang. Perubahan Kebun Raya yang bersifat heterogin sama saja merubah ekosistem yang sudah terbentuk bertahun-tahun, perlu penanganan lebih konservatif (1) Pengelolaan Kebun Raya Baturraden harus dilaksanakan bertahap tidak boleh dilakukan penebangan pohon secara besar besaran seperti yang sedang dilakukan saat ini karena kondisi tanah dilokasi rawan longsor (2).Dengan kondisi tegakan pohon sangat rapat untuk melakukan tebangan sebaiknya menggunakan tebangan penerangan atau penjarangan jangan sampai tanah terbuka mengingat mempunyai curah hujan tinggi. (3). Agar tidak terjadi erosi tanah yang berlebihan perlu ada terasering dibagian yang rawan terjadi kelongsoran tanah.

\section{DAFTAR PUSTAKA}

Andrian, Supriadi, Purba Marpaung, 2014, The Effect of Elevation and Slope on Rubber (Hevea brasiliensisMuell. Arg.) Production in PTPN III Hapesong Farm of South Tapanuli, Juni 2014, Jurnal Agroekoteknologi . ISSN No. 2337-6597Vol.2, No.3 : 981-989.

Arsyad S., 2006. Konservasi Tanah dan Air. IPB Press, Bogor.

Anonim, 1990. Undang-undang Nomor : 5 Tahun 1990 tentang Konservasi Sumber Daya Alam Hayati dan Ekosistemnya. Jakarta.

Anonim, 2010, Peraturan Pemerintah Republik Indonesia Nomor 10 Tahun 2010

Anonim, 2011, Tentang Kebun raya, Peraturan Presiden Republik Indonesia Nomor 93 Tahun 2011

Anonim, 2007 b. Wanawisata. Perum Perhutani KPH Banyumas Timur.

Heywood, V.H. and Watson, R.T. 1995. Global biodiversity assessment. Cambridge Univ. Press for the United Nations Environment Program UNEP, Cambridge.

Martono. 2006. Pengaruh Intensitas Hujan dan Kemiringan Lereng Terhadap Laju Kehilangan Tanah Pada Tanah Regosol Kelabu. Universitas Diponegoro,

Semarang.

Moch. Arifin, 2010, Kajian sifat fisik tanah dan berbagai penggunaan lahan dalam hubungan dengan pendugaan erosi tanah, Jurnal Pertanian MAPETA, ISSN : 1411-2817, Vol. XII. No. 2. 72 - 144

Poerbandono, Basyar A, Agung B.H dan Rallyanti P, 2008, Evaluasi Perubahan Perilaku Erosi Daerah Aliran Sungai Citarum Hulu dengan Pemodelan Spasial, Jurnal Infrastruktur dan Lingkungan binaan infrastruktur dan Lingkungan, Binaan Infrastrukture and Built Enviroment Vol II No 2

PROC. ITB Sains \& Tek. Vol. 39 A, No. 1\&2, 2007, 97-123 